\title{
THE CAPACITATED NEWSBOY PROBLEM WITH REVENUE SHARING
}

\author{
BARRY A. PASTERNACK $\dagger$ \\ Department of MS/IS, California State University-Fullerton, CA 92834
}

\begin{abstract}
In this paper we consider a single inventory (newsboy) problem in which the vendor has a limited amount of funds to purchase items to sell. We assume that the manufacturer will either sell the items to the vendor outright or offer the items to the vendor on a revenue sharing (consignment) basis. In the latter case, that amount of money the vendor pays per unit is less than if the items are purchased from the vendor, but the vendor must share some of the revenue with the manufacturer. The purpose of our analysis is to investigate under what circumstances, it would pay for the vendor to only purchase the items from the manufacturer, only take the items on consignment from the manufacturer, or both purchase and take consignment shipments form the manufacturer.
\end{abstract}

Keywords: newsboy, channel coordination, consignment, revenue sharing.

\section{Introduction}

This paper investigates the situation in which a vendor, in a newsboy-type situation, has the option of purchasing the item outright and/or obtaining the item through a revenue sharing agreement with the manufacturer. Of specific interest are the implications of the vendor having limited funds available for item.

The motivation for this paper comes from an article in the March 25, 1998 edition of the Wall Street Journal dealing with the concept of revenue sharing at video rental stores. The article describes efforts by Blockbuster Video to obtain tapes from Hollywood studios on a revenue sharing basis. The article cites research by Time Warner that indicates $20 \%$ of customers are unable to obtain their first choice video due to a stock out situation. To remedy this situation, stores are being offered videotapes for $\$ 8$ each on a revenue sharing basis versus $\$ 65$ each for outright purchase.

The purpose of this article is to examine the strategy of revenue sharing for a newsboy (single period) inventory model. In particular, we wish to

$\dagger$ Requests for reprints should be sent to B. A. Pasternack, Department of MS/IS, School of Business Administration and Economics, California State University, Fullerton, CA 92834 
examine the effect that available funding has on the decision to purchase the item outright versus obtaining the item on consignment.

Drezner and Pasternack [1999] demonstrated that the newsboy problem and the video rental problem are analogous. The newsboy (single period) inventory model is well researched in the literature and contained in most introductory management science texts (see for example Lawrence and Pasternack [1998]). There have been numerous papers in the literature dealing with the extensions to this model. Silver, Pike, and Peterson [1998] have a partial review of the literature in their textbook. Khouja [1999] contains an extensive review of the literature dealing with such extensions. In this paper Khouja reviewed some 90 publications and classified them into eleven categories based on the type of extension to the classical newsboy problem. Following Khouja's classification, this paper would fall into two categories; those dealing with constrained multi-product and those dealing with different supplier pricing policies.

In the category of extensions dealing with constrained multi-product, the current paper differs from the previous literature in that while we consider constraints on available capital, we are only considering a single product. In terms of extensions in which the vendor stocks different items, Lau and Lau [1996] considered the situation of a vendor stocking several items subject to a set of resource constraints. Using a Lagrangian approach, they developed solution procedures and presented examples based on the uniform, exponential, and normal distributions.

Extensions to the newsboy problem in terms of different supplier pricing policies have focused on quantity discounts (see for example Jucker and Rosenblatt [1985] and Lin and Kroll [1997]), permitting emergency supplies obtainable at a premium cost over the original cost per unit (see for example, Khouja [1996]), and multiple suppliers (see for example, Kabak and Weinberg [1972]).

This paper differs from the previous literature in that we assume that the vendor is selling only one item, but has the option of purchasing the good outright, obtaining the good on a revenue sharing (consignment) basis, or doing a combination of both. Our analysis will examine the structure of the optimal inventory policy. In particular we are interested in determining: 1) under what conditions obtaining the goods through outright purchase would not be optimal, 2) under what conditions only obtaining the item on a consignment basis would not be optimal, and 3) under what conditions obtaining the good through a combination of outright purchase and consignment is optimal. In this latter case we will determine formulas for the vendor's optimal order quantities for outright purchase and consignment. 
In Section 2 we introduce the general model. In Section 3 we demonstrate that under some general conditions, it will be optimal for the vendor to only obtain the item on consignment if the amount of available funds is low and only obtain the item through outright purchase if the amount of available funds is high. In between these extremes it will be optimal for the vendor to obtain the item through a combination of outright purchase and consignment. An example is presented demonstrating these cases. Concluding remarks are presented in Section 4.

\section{The Model}

In this section we introduce the general model. Operationally, because the vendor will earn a greater profit on the units it obtains through outright purchase, we assume that the vendor will first sell the goods it purchases outright and will only sell those it obtains on consignment after all purchased units have been sold. The basis for our analysis is to investigate the Kuhn-Tucker conditions in order to determine optimal strategies.

The notation we use is as follows:

$p_{1}$ the retail price per unit $\left(p_{1}\right.$ is therefore the vendor's revenue per unit if the vendor obtains the item from the manufacturer though outright purchase)

$c_{1}$ the vendor's cost per unit if the vendor obtains the item from the manufacturer through outright purchase

$s$ the vendor's salvage value per unit if the vendor obtains the item from the manufacturer through outright purchase

$g$ the vendor's goodwill cost per unit if the vendor is out of stock of the item

$m$ the manufacturer's production cost per unit

$p_{2}$ the vendor's revenue per unit if the vendor obtains the item from the manufacturer on consignment $\left(p_{1}-p_{2}=\right.$ the revenue paid to the manufacturer if an item purchased on consignment is sold by the vendor)

$c_{2}$ the vendor's cost per unit if the vendor obtains the item from the manufacturer on consignment

$Q_{1}$ the number of units the vendor obtains from the manufacturer through outright purchase 
$Q_{2}$ the number of units the vendor obtains from the manufacturer on consignment

$T$ the total amount of funds the vendor has available for obtaining the item through either outright purchase or consignment

$E V\left(Q_{1}, Q_{2}\right)$ the vendor's expected profit if it purchases $Q-1$ units and obtains $Q-2$ units on consignment

$Q_{1}^{*}$ the optimal number of units the vendor should obtain from the manufacturer through outright purchase if the vendor wishes to maximize its expected profit

$Q_{2}^{*}$ the optimal number of units the vendor should obtain from the manufacturer on consignment if the vendor wishes to maximize its expected profit

$f(x)$ the probability density function of demand

Following this notation, we see that if the vendor purchases the item outright from the manufacturer, the vendor earns net revenue of $p_{1}-c_{1}$ for each unit sold while the manufacturer earns net revenue of $c_{1}-m$ for each unit ordered by the manufacturer. If however, the vendor orders the item from the manufacturer on a consignment basis, the vendor pays the manufacturer an amount of $c_{2}$ per unit plus an amount equal to $p_{1}-p_{2}$ for each unit sold. As a result, for items obtained on consignment and sold by the vendor, the vendor earns a net revenue per unit of $p_{2}-c_{2}$ and the manufacturer earns a net revenue per unit of $p_{1}-p_{2}+c_{2}-m$.

We also assume that if the item is purchased outright from the manufacturer, then the salvage value, $s$, from any unsold units accrues to the vendor, whereas if the item is obtained from the manufacturer on a consignment basis then the salvage value accrues to the manufacturer. This assumption is made since items obtained on consignment are actually owned by the manufacturer and are therefore returned to the manufacturer if unsold. In all cases the goodwill cost per unit, $g$, is assumed to accrue to the vendor.

The following conditions are assumed to hold regarding $p_{1}, p_{2}, c_{1}, c_{2}$, and $s$.

$p_{1}>p_{2}$ (The vendor's revenue per unit is greater if it purchases the item than if it obtains the item on consignment.)

$c_{1}>c_{2}$ (The vendor's cost per unit is greater if it purchases the item than if obtains the item on consignment.) 
$c_{1}>s$ (The vendor's cost per unit for purchasing the item is greater than its salvage value)

$p_{1}>c_{1}$ (For items purchased, the vendor's revenue per unit is greater than the cost per unit.)

$p_{1}-p_{2}>c_{1}-c_{2}$ (For it to be worthwhile for the manufacture to offer the item to the vendor on a consignment basis, the manufacturer's revenue per unit from consignment should be at least as great as from outright sale to the vendor. This implies that the vendor's profit per unit from outright purchase is greater than if it obtains the item on consignment.)

Note that we will not require $p_{2}>c_{2}$. That is, for items obtained on consignment, the vendor's revenue per unit may be less than the cost per unit. While such a situation would rarely arise, it is conceivably possible that it may be worthwhile for the vendor to obtain goods on consignment even if they will be sold at a loss in order to avoid the potential of incurring extremely high goodwill costs.

Based on the above notation, we have:

$$
\begin{aligned}
E V\left(Q_{1}, Q_{2}\right) & =\int_{0}^{Q_{1}}\left[p_{1} x+s\left(Q_{1}-x\right)\right] f(x) d x \\
& +\int_{Q_{1}}^{Q_{1}+Q_{2}}\left[\left(p_{1}-p_{2}\right) Q_{1}+p_{2} x\right] f(x) d x \\
& +\int_{Q_{1}+Q_{2}}^{\infty}\left[p_{1} Q_{1}+p_{2} Q_{2}-g\left(x-Q_{1}-Q_{2}\right)\right] f(x) d x \\
& -c_{1} Q_{1}-c_{2} Q_{2}
\end{aligned}
$$

The problem faced by the vendor is therefore:

$$
\text { Maximize }\left\{E V\left(Q_{1}, Q_{2}\right)\right\}
$$

Subject to:

$$
\begin{gathered}
c_{1} Q_{1}+c_{2} Q_{2} \leq T \\
-Q_{1} \leq 0 \\
-Q_{2} \leq 0
\end{gathered}
$$

The partial derivatives of $E V\left(Q_{1}, Q_{2}\right)$ are as follows: 


$$
\frac{\partial E V\left(Q_{1}, Q_{2}\right)}{\partial Q_{1}}=F\left(Q_{1}\right)\left(s-p_{1}+p_{2}\right)-F\left(Q_{1}+Q_{2}\right)\left(p_{2}+g\right)-c_{1}+p_{1}+g
$$

and

$$
\frac{\partial E V\left(Q_{1}, Q_{2}\right)}{\partial Q_{2}}=\left[1-F\left(Q_{1}+Q_{2}\right)\right]\left(p_{2}+g\right)-c_{2}
$$

Based on this, the following Kuhn-Tucker conditions are required for optimality:
1) $Y_{1}\left(T-c_{1} Q_{1}^{*}-c_{2} Q_{2}^{*}\right)=0$
2) $Y_{2} Q_{1}^{*}=0$
3) $Y_{3} Q_{2}^{*}=0$
4) $F\left(Q_{1}^{*}\right)\left(s-p_{1}+p_{2}\right)-F\left(Q_{1}^{*}+Q_{2}^{*}\right)\left(p_{2}+g\right)-c_{1}+p_{1}+g=Y_{1} c_{1}-Y_{2}$
5) $\left[1-F\left(Q_{1}^{*}+Q_{2}^{*}\right)\right]\left(p_{2}+g\right)-c_{2}=Y_{1} c_{2}-Y_{3}$
6) $Y_{1} \geq 0, Y_{2} \geq 0, Y_{3} \geq 0, Q_{1}^{*} \geq 0, Q_{2}^{*} \geq 0$

Looking at the partial second derivatives for $E V\left(Q_{1}, Q_{2}\right)$, we have:

$$
\begin{aligned}
& \frac{\partial^{2} E V\left(Q_{1}, Q_{2}\right)}{\partial Q_{1}^{2}}=f\left(Q_{1}\right)\left(s-p_{1}+p_{2}\right)-f\left(Q_{1}, Q_{2}\right)\left(p_{2}+g\right) \\
& \frac{\partial^{2} E V\left(Q_{1}, Q_{2}\right)}{\partial Q_{2}^{2}}=-f\left(Q_{1}, Q_{2}\right)\left(p_{2}+g\right)
\end{aligned}
$$

and

$$
\frac{\partial^{2} E V\left(Q_{1}, Q_{2}\right)}{\partial Q_{1} \partial Q_{2}}=-f\left(Q_{1}, Q_{2}\right)\left(p_{2}+g\right)
$$

Hence, if $p_{1}-p_{2}-s \geq 0, E V\left(Q_{1}, Q_{2}\right)$ is concave.

\section{Optimal Strategies When the Vendor's Available Funds Are Limited}

Our interest lies in determining the structure of the optimal strategy for the vendor. We assume that $T$ is fully expended for procurement (i.e. $T=c_{1} Q_{1}^{*}+c_{2} Q_{2}^{*}$ ) and focus on the conditions that lead to the vendor only purchasing the item, only obtaining the item on consignment, and obtaining the item through both outright purchase and consignment. 
THEOREM 1 If $T=c_{1} Q_{1}^{*}+c_{2} Q_{2}^{*}$ and $\frac{c_{1}}{c_{2}}>\frac{p_{1}-s}{p_{2}}$ then it is impossible for $Q_{1}^{*}>0$ and $Q_{2}^{*}=0$.

Proof: We will utilize a proof by contradiction. Suppose $Q_{1}^{*}>0$ and $Q_{2}^{*}=0$. Then from K-T condition 5) we have:

$$
F\left(Q_{1}^{*}\right)=\frac{p_{2}+g-c_{2}\left(1+Y_{1}\right)+Y_{3}}{p_{2}+g}
$$

While from K-T condition 4) we have:

$$
F\left(Q_{1}^{*}\right)=\frac{p_{1}+g-c_{1}\left(1+Y_{1}\right)}{p_{1}+g-s}
$$

Equating the two expressions for $F\left(Q_{1}^{*}\right)$ gives:

$$
Y_{3}=\left(1+Y_{1}\right)\left(c_{2}-\frac{c_{1}\left(p_{2}+g\right)}{p_{1}+g-s}\right)
$$

This results in $Y_{3}$ being negative if $\frac{c_{1}}{c_{2}}>\frac{p_{1}-s}{p_{2}}$.

Theorem 1 states that if the ratio of the cost of purchasing the item to the cost of obtaining the item on consignment were high enough, it would never pay to only purchase the item.

THEOREM 2 If $T=c_{1} Q_{1}^{*}+c_{2} Q_{2}^{*}$ and $\frac{p_{2}+g}{c_{2}}<\frac{p_{1}-p_{2}}{c_{1}-c_{2}}$ then it is impossible for $Q_{1}^{*}=0$ and $Q_{2}^{*}>0$.

Proof: We will again use a proof by contradiction. Suppose $Q_{1}^{*}=0$ and $Q_{2}^{*}>0$. Then from K-T condition 5) we have:

$$
F\left(Q_{2}^{*}\right)=\frac{p_{2}+g-c_{2}\left(1+Y_{1}\right)}{p_{2}+g}
$$

while from K-T condition 4) we have:

$$
F\left(Q_{2}^{*}\right)=\frac{p_{1}+g-c_{1}\left(1+Y_{1}\right)+Y_{2}}{p_{2}+g}
$$

Equating the two expressions for $F\left(Q_{2}^{*}\right)$ gives:

$$
1+Y_{1}=\frac{Y_{2}-p_{2}+p_{1}}{c_{1}-c_{2}}
$$

Substituting this expression back into the first expression for $F\left(Q_{2}^{*}\right)$ gives:

$$
F\left(Q_{2}^{*}\right)=1-\frac{c_{2}\left(p_{1}-p_{2}+Y_{2}\right)}{\left(c_{1}-c_{2}\right)\left(p_{2}+g\right)}
$$


Hence, we must have:

$$
Y_{2}<\frac{\left(c_{1}-c_{2}\right)\left(p_{2}+g\right)}{c_{2}}-p_{1}+p_{2}
$$

But, if $\frac{p_{2}+g}{c_{2}}<\frac{p_{1}-p_{2}}{c_{1}-c_{2}}$, we would have $Y_{2}<0$.

Theorem 2 states that if the profit margin on goods purchased is substantially higher than the profit margin on goods obtained on consignment and if the goodwill cost is small, it would never pay to only obtain the goods on consignment.

The next theorem examines the situation in which it will be optimal for the vendor to only obtain the item using consignment if it has a small amount of funds and only obtain the item through outright purchase if it has a large amount of funds. Between these extremes, the vendor will obtain the item through a combination of consignment and outright purchase.

THEOREM 3 If $T=c_{1} Q_{1}^{*}+c_{2} Q_{2}^{*}, p_{1}-p_{2}>s, \frac{p_{1}+g-c_{1}}{p_{1}+g-s}>\frac{p_{2}+g-c_{2}}{p_{2}+g}$, and $\frac{p_{2}+g}{c_{2}}>\frac{p_{1}-p_{2}}{c_{1}-c_{2}}$, Then

a) $Q_{1}^{*}=0$ and $Q_{2}^{*}=\frac{T}{c_{2}}$ if $T$ is such that $F\left(\frac{T}{c_{2}}\right) \leq 1-\frac{c_{2}\left(p_{1}-p_{2}\right)}{\left(c_{1}-c_{2}\right)\left(p_{2}+g\right)}$ and

b) $Q_{1}^{*}=\frac{T}{c_{1}}$ and $Q_{2}^{*}=0$ if $T$ is such that $1-\frac{s c_{2}}{p_{2} c_{1}-p_{1} c_{2}+g\left(c_{1}-c_{2}\right)+s c_{2}} \leq$ $F\left(\frac{T}{c_{1}}\right) \leq \frac{p_{1}+g-c_{1}}{p_{1}+g-s}$. If $F\left(\frac{T}{c_{2}}\right)>1-\frac{c_{2}\left(p_{1}-p_{2}\right)}{\left(c_{1}-c_{2}\right)\left(p_{2}+g\right)}$ and $1-\frac{s c_{2}}{p_{2} c_{1}-p_{1} c_{2}+g\left(c_{1}-c_{2}\right)+s c_{2}}>$ $F\left(\frac{T}{c_{1}}\right)$ then $Q_{1}^{*}$ and $Q_{2}^{*}$ are both greater than 0 and satisfy the following relationships:

$F\left(Q_{1}^{*}\right)=\frac{p_{1}-p_{2}+\left(c_{2}-c_{1}\right)\left(1+Y_{1}\right)}{p_{1}-p_{2}-s}$ and $F\left(Q_{1}^{*}+Q_{2}^{*}\right)=\frac{p_{2}+g-c_{2}\left(1+Y_{1}\right)}{p_{2}+g}$.

(where $Y 1 \geq 0$ ).

Proof: Let us divide this proof into two parts. First, we consider the case where $F\left(\frac{T}{c_{2}}\right) \leq 1-\frac{c_{2}\left(p_{1}-p_{2}\right)}{\left(c_{1}-c_{2}\right)\left(p_{2}+g\right)}$. We will show that $Q_{1}^{*}=0$ and $Q_{2}^{*}=\frac{T}{c_{2}}$ satisfy the Kuhn-Tucker conditions. In particular, in this case $Y_{3}=0$ and therefore from K-T condition 5) we have:

$$
F\left(Q_{2}^{*}\right)=\frac{p_{2}+g-c_{2}\left(1+Y_{1}\right)}{p_{2}+g}
$$

Substituting this relationship into K-T condition 4) gives the relationship:

$$
1+Y_{1}=\frac{p_{1}-p_{2}+Y_{2}}{c_{1}-c_{2}}
$$


Substituting this relationship back into K-T condition 5) gives the desired result:

$$
F\left(Q_{2}^{*}\right)=\frac{p_{2} c_{1}-p_{1} c_{2}+g\left(c_{1}-c_{2}\right)-Y_{2} c_{2}}{\left(c_{1}-c_{2}\right)\left(p_{2}+g\right)} \leq 1-\frac{c_{2}\left(p_{1}-p_{2}\right)}{\left(c_{1}-c_{2}\right)\left(p_{2}+g\right)} .
$$

Now let us consider the case in which

$$
1-\frac{s c_{2}}{p_{2} c_{1}-p_{1} c_{2}+g\left(c_{1}-c_{2}\right)+s c_{2}} \leq F\left(\frac{T}{c_{1}}\right) \leq \frac{p_{1}+g-c_{1}}{p_{1}+g-s}
$$

We wish to show that $Q_{1}^{*}=\frac{T}{c_{1}}$ and $Q_{2}^{*}=0$ satisfy the Kuhn-Tucker conditions. If this is the case, $Y_{2}^{c_{1}}=0$ and from K-T condition 5):

$$
F\left(Q_{1}^{*}\right)=\frac{p_{2}+g-c_{2}\left(1+Y_{1}\right)+Y_{3}}{p_{2}+g}
$$

¿From K-T condition 4) we have:

$$
F\left(Q_{1}^{*}\right)=\frac{p_{1}+g-c_{1}\left(1+Y_{1}\right)}{p_{1}+g-s}
$$

Equating these two expressions for $F\left(Q_{1}^{*}\right)$ gives the relationship:

$$
1+Y_{1}=\frac{s\left(p_{2}+g\right)-Y_{3}\left(p_{1}+g-s\right)}{c_{1} p_{2}-c_{2} p_{1}+g\left(c_{1}-c_{2}\right)+c_{2} s}
$$

Substituting this relationship back into the relationship for $F\left(Q_{1}^{*}\right)$ determined by K-T condition 5) gives:

$F\left(Q_{1}^{*}\right)=\frac{c_{1} p_{2}-c_{2} p_{1}+g\left(c_{1}-c_{2}\right)+Y_{3} c_{1}}{c_{1} p_{2}-c_{2} p_{1}+g\left(c_{1}-c_{2}\right)+c_{2} s} \geq 1-\frac{s c_{2}}{p_{2} c_{1}-p_{1} c_{2}+g\left(c_{1}-c_{2}\right)+s c_{2}}$

To show that $F\left(\frac{T}{c_{1}}\right) \leq \frac{p_{1}+g-c_{1}}{p_{1}+g-s}$, we note that from the relationship for $F\left(Q_{1}^{*}\right)$ determined from K-T condition 5$), F\left(Q_{1}^{*}\right)$ is decreasing in $Y_{1}$. If $Y_{1}=0$, then

$$
F\left(Q_{1}^{*}\right)=\frac{p_{2}+g-c_{2}+Y_{3}}{p_{2}+g}
$$

and

$$
1=\frac{s\left(p_{2}+g\right)-Y_{3}\left(p_{1}+g-s\right)}{c_{1} p_{2}-c_{2} p_{1}+g\left(c_{1}-c_{2}\right)+c_{2} s}
$$

Solving this latter relationship for $Y_{3}$ and substituting the value for $Y_{3}$ back into the expression for $F\left(Q_{1}^{*}\right)$, gives the result that $F\left(Q_{1}^{*}\right) \leq \frac{p_{1}+g-c_{1}}{p_{1}+g-s}$. 


\subsection{An Example}

The following example serves to illustrate the results of Theorem 3 .

Suppose $p_{1}=\$ 100, p_{2}=\$ 60, c_{1}=\$ 40, c_{2}=\$ 30, s=\$ 10, g=\$ 100$, and $f(x)=U(0,95)$.

From Theorem 3 we see that if the value of $T$ is such that $F\left(\frac{T}{c_{2}}\right) \leq \frac{1}{4}$, then the vendor's optimal decision is to order $Q_{1}^{*}=0$ and $Q_{2}^{*}=\frac{T}{c_{2}}$. If the value of $T$ is such that $\frac{4}{7} \leq F\left(\frac{T}{c_{1}}\right) \leq \frac{16}{19}$, then the vendor's optimal decision is to order $Q_{1}^{*}=\frac{T}{c_{1}}$ and $Q_{2}^{*}=0$. For values of $T$ such that $F\left(\frac{T}{c_{2}}\right)>\frac{1}{4}$ and $F\left(\frac{T}{c_{1}}\right)<\frac{4}{7}$, the vendor's optimal ordering decision is found by solving the following two equations:

$$
\begin{gathered}
F\left(Q_{1}^{*}+Q_{2}^{*}\right)=\frac{p_{2}+g-c_{2}\left(1+Y_{1}\right)}{p_{2}+g} \\
F\left(Q_{1}^{*}\right)=\frac{p_{1}-p_{2}+\left(c_{2}-c_{1}\right)\left(1+Y_{1}\right)}{p_{1}-p_{2}-s}
\end{gathered}
$$

where $Y_{1} \geq 0$.

For the given values, we see that if $T<\frac{\$ 30 \times 95}{4}=\$ 712.50$, the optimal strategy would be for the vendor to only obtain the items on consignment. Alternatively, if $T$ is between $\frac{\$ 40 \times 95 \times 4}{7}=\$ 2,171.43$ and $\$ 3,200$ the vendor should only obtain the items through outright purchase. (Note that for amounts over $\$ 3,200$ the vendor would still only obtain the item through outright purchase, but would not use all available funds.)

For amounts between $\$ 712.50$ and $\$ 2171.43$, the optimal strategy would be for the vendor to purchase some items outright and to obtain some on consignment. For example, if the vendor has $\$ 1,200$ available, the vendor's optimal decision is determined by solving the equations:

$$
\frac{Q_{1}^{*}}{95}=\frac{30-10 Y_{1}}{30}, \frac{Q_{1}^{*}+Q_{2}^{*}}{95}=\frac{130-30 Y_{1}}{160}, \text { and } 40 Q_{1}^{*}+30 Q_{2}^{*}=1,200 .
$$

This gives the result that $Y_{1}=2.4272, Q_{1}^{*}=18.1395 \approx 18$ and $Q_{2}^{*}=$ $15.8139 \approx 16$. Note that the value of $Y_{1}$ represents the marginal change in the vendor's expected profit due to a change in available funding.

Now let us examine under what circumstances it would never pay for the vendor to only obtain the item through outright purchase. Theorem 4 addresses this case. 
Theorem 4 If $T=c_{1} Q_{1}^{*}+c_{2} Q_{2}^{*}, p_{1}-p_{2}>s, \frac{p_{1}+g-c_{1}}{p_{1}+g-s} \leq \frac{p_{2}+g-c_{2}}{p_{2}+g}$, and $\frac{p_{2}+g}{c_{2}}>\frac{p_{1}-p_{2}}{c_{1}-c_{2}}$, then $Q_{1}^{*}=0$ and $Q_{2}^{*}=\frac{T}{c_{2}}$ if $T$ is such that $F\left(\frac{T}{c_{2}}\right) \leq$ $1-\frac{c_{2}\left(p_{1}-p_{2}\right)}{\left(c_{1}-c_{2}\right)\left(p_{2}+g\right)}$, otherwise $Q_{1}^{*}$ and $Q_{2}^{*}$ are both greater than 0 and satisfy the following relationships:

$F\left(Q_{1}^{*}\right)=\frac{p_{1}-p_{2}+\left(c_{2}-c_{1}\right)\left(1+Y_{1}\right)}{p_{1}-p_{2}-s}$ and $F\left(Q_{1}^{*}+Q_{2}^{*}\right)=\frac{p_{2}+g-c_{2}\left(1+Y_{1}\right)}{p_{2}+g}$,

where $Y_{1} \geq 0$.

Proof: The proof of this theorem is nearly identical to Theorem 3. The only difference is that we wish to show that it is impossible for $Q_{1}^{*}>0$ and $Q_{2}^{*}=0$. To do this we note that if $Q_{1}^{*}>0$ and $Q_{2}^{*}=0$, then from K-T condition 5),

$$
F\left(Q_{1}^{*}\right)=\frac{p_{2}+g-c_{2}\left(1+Y_{1}\right)+Y_{3}}{p_{2}+g}
$$

while from K-T condition 4) we have

$$
F\left(Q_{1}^{*}\right)=\frac{p_{1}+g-c_{1}\left(1+Y_{1}\right)}{p_{2}+g-s}
$$

However, from the assumption that $\frac{p_{2}+g}{c_{2}}>\frac{p_{1}-p_{2}}{c_{1}-c_{2}}$, we know that $p_{2} c_{1}+$ $g c_{1}>p_{1} c_{2}-s c_{2}+g c_{2}$, or equivalently, that $\frac{c_{2}}{p_{2}+g}<\frac{c_{1}}{p_{1}+g-s}$. Therefore it would be impossible for $F\left(Q_{1}^{*}\right)$ to be both equal to $\frac{p_{2}+g-c_{2}\left(1+Y_{1}\right)+Y_{3}}{p_{2}+g}$ as well as $\frac{p_{1}+g-c_{1}\left(1+Y_{1}\right)}{p_{2}+g-s}$.

Theorem 4 states is that under the given conditions, if the funding level is low enough the vendor will obtain all items through consignment, otherwise the vendor will obtain items through both outright purchase and consignment.

\subsection{An Example}

The following example illustrates the results of Theorem 4 .

Suppose $p_{1}=\$ 100, p_{2}=\$ 60, c_{1}=\$ 40, c_{2}=\$ 20, s=\$ 10, g=\$ 100$, and $f(x)=U(0,95)$.

¿From Theorem 4 we see that if the value of $T$ is such that $F\left(\frac{T}{c_{2}}\right) \leq \frac{3}{4}$ then the vendor's optimal decision is to order $Q_{1}^{*}=0$ and $Q_{2}^{*}=\frac{T}{c_{2}}$. If the 
value of $T$ is such that $F\left(\frac{T}{c_{2}}\right) \geq \frac{3}{4}$, then the vendor's optimal decision is found by solving the following two equations:

$$
\begin{gathered}
F\left(Q_{1}^{*}+Q_{2}^{*}\right)=\frac{p_{2}+g-c_{2}\left(1+Y_{1}\right)}{p_{2}+g} \\
F\left(Q_{1}^{*}\right)=\frac{p_{1}-p_{2}+\left(c_{2}-c_{1}\right)\left(1+Y_{1}\right)}{p_{1}-p_{2}-s}
\end{gathered}
$$

where $Y_{1} \geq 0$.

For the given values, we see that if $T<\frac{\$ 20 \times 95 \times 3}{4}=\$ 1,425.00$, the optimal strategy would be for the vendor to only obtain the items on consignment. For amounts over $\$ 1,425.00$ the vendor would both purchase items outright and obtain items on consignment.

For example, if the vendor has $\$ 1,600$ available, the vendor's optimal decision is determined by solving the equations:

$$
\frac{Q_{1}^{*}}{95}=\frac{20-20 Y_{1}}{30}, \frac{Q_{1}^{*}+Q_{2}^{*}}{95}=\frac{70-10 Y_{1}}{80}, \text { and } 40 Q_{1}^{*}+20 Q_{2}^{*}=1,600 .
$$

This gives the result $Q_{1}^{*}=7.3684 \approx 7$ and $Q_{2}^{*}=72.6316 \approx 73$.

\section{Conclusion}

This paper has dealt with the structure of the vendor's strategy when faced with a limitation on obtaining inventory items in a newsboy situation. We have given conditions under which it would never pay for the vendor to only obtain the item on consignment and conditions under which it would never pay for the vendor to only obtain the item through outright purchase. We also showed that there exist a set of conditions under which the vendor's optimal strategy will change based on the amount of available capital for inventory procurement. In these circumstances, if the vendor has a small amount of available capital only procuring the item through consignment will be optimal whereas if the capital reaches a certain threshold amount, a mixed strategy that includes both obtaining the item on consignment and through outright purchase makes sense. We also show that under some circumstances, a vendor having adequate funding will only obtain the item through outright purchase.

While the focus of this paper has been on the vendor, further study of the effects on the channel from a consignment scheme are worthy of study. For example, one issue of interest is the effect offering consignment goods has on the manufacturer's profit and whether a consignment scheme can be used to achieve channel coordination. 


\section{References}

1. Drezner, Z and Pasternack, B.A., (1999), "The Videotape Rental Model", Journal of Applied Mathematics \& Decision Sciences, 3(2), 167 - 174.

2. Jeuland, A. P. and Shugan, S. M. (1983), "Managing Channel Profits", Marketing Science, 2, 239-272.

3. Jucker, J. V. and Rosenblatt, M. J. (1985), "Single-Period Inventory Models with Demand Uncertainty and Quantity Discounts: Behavioral Implications and a New Solution Procedure", Naval Research Logistics Quarterly, 32, 537-550.

4. Kaback, I. and Weinberg, C. (1972), "The Generalized Newsboy Problem, Contract Negotiations, and Secondary Vendors," IIE Transactions, 4, 154-157.

5. Khouja, M. (1996), "The Newsboy Problem with Progressive Retailer Discounts and Supplier Quantity Discounts", Decision Science, 27, 589-599.

6. Khouja, M. (1999), "The Single-Period (News-Vendor) Problem: Literature Review and Suggestions for Future Research", Omega, 27, 537-553.

7. Lau, H. and Lau, A. H. (1996), "The Newstand Problem: A Capacitated MultipleProduct Single-Period Inventory Problem", European Journal of Operational Research, 94, 29-42.

8. Lawrence, J. A. and Pasternack, B. A. (1998), Applied Management Science, A Computer Integrated Approach for Decision Making, New York, John Wiley \& Sons.

9. Lin, C. and Kroll, D. E. (1997), "The Single-Item Newsboy Problem with Dual Performance Measures and Quantity Discounts", European Journal of Operational Research, 100, 562-565.

10. Monahan, J. P. (1984), "A Quantity Discount Pricing Model to Increase Vendor Profits", Management Science, 30, 720-726.

11. Pasternack, B. A. (1985), "Optimal Pricing and Return Policies for Perishable Commodities", Marketing Science, 4, 166-176.

12. Silver, E.A., Pyke, D.F., and Peterson, R. P. (1998), Inventory Management and Production Planning and Scheduling, Third Edition, New York, John Wiley \& Sons. 


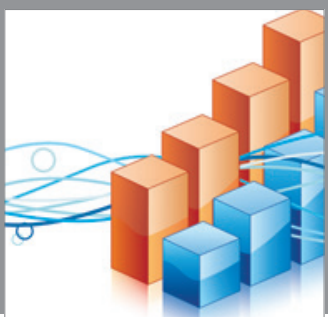

Advances in

Operations Research

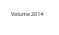

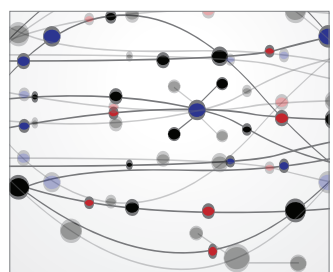

\section{The Scientific} World Journal
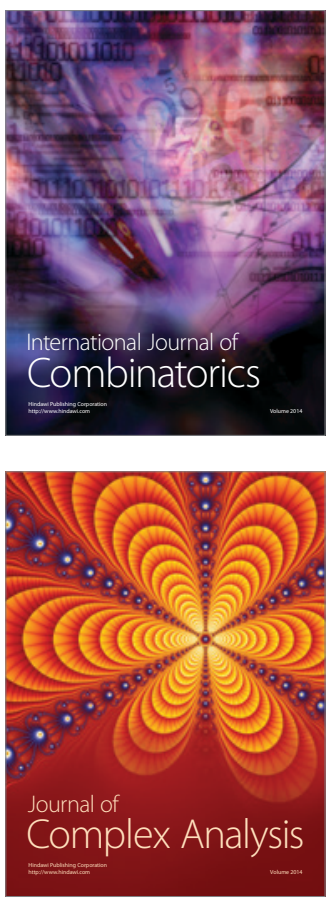

International Journal of

Mathematics and

Mathematical

Sciences
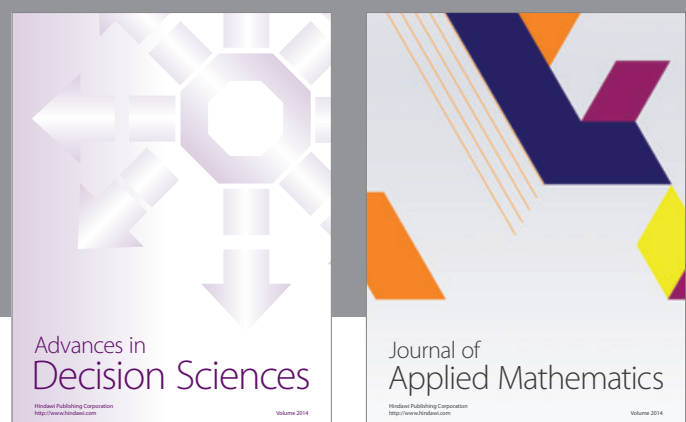

Journal of

Applied Mathematics
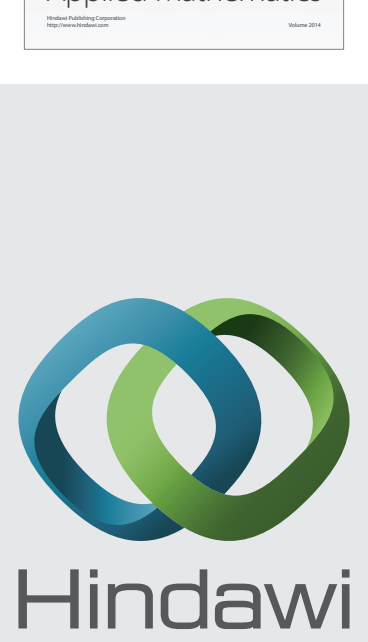

Submit your manuscripts at http://www.hindawi.com
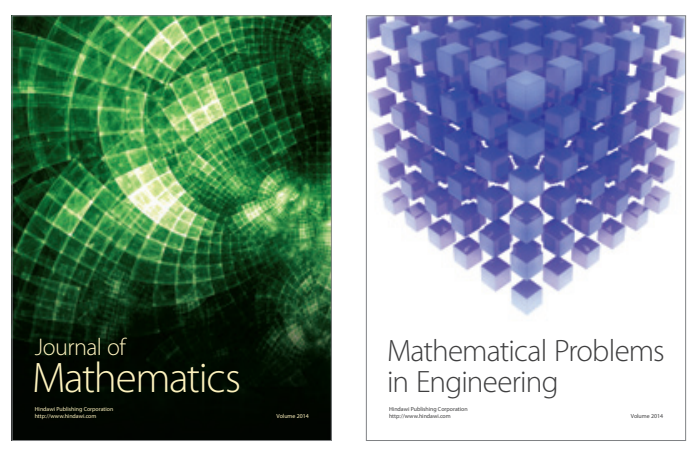

Mathematical Problems in Engineering
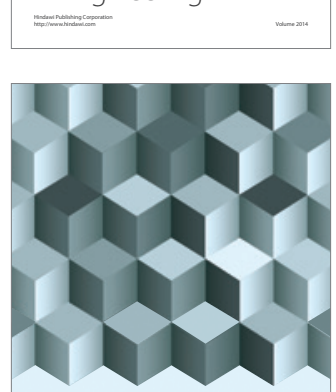

Journal of

Function Spaces
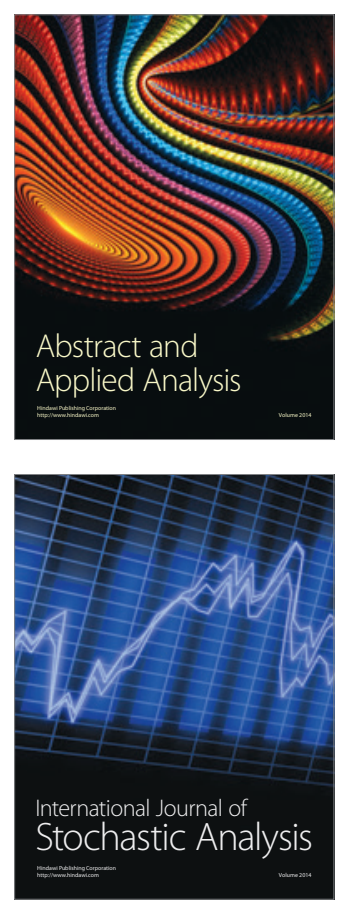

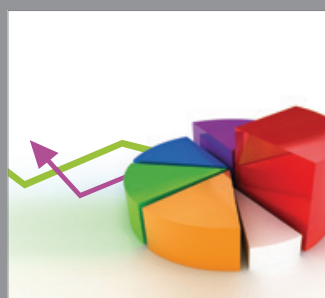

ournal of

Probability and Statistics

Promensencen
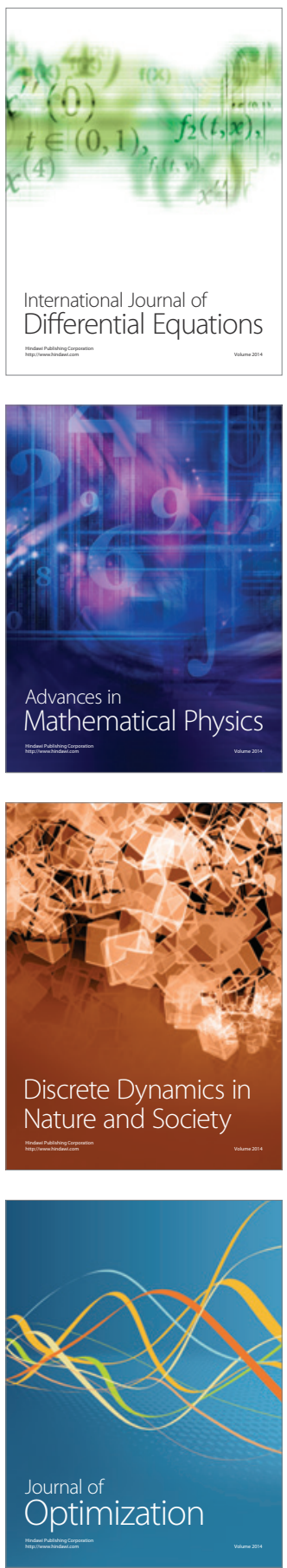